Jpn. J. Human Genet. 34, 297-305, 1989

\title{
SATELLITED CHROMOSOME 9 IN A BOY WITH MULTIPLE ANOMALIES
}

\author{
Naoki Harada, ${ }^{1,3}$ Kyohko ABE, ${ }^{1,3}$ \\ Tatsuro KondoH, ${ }^{1,2}$ Tetsuya Hirota, ${ }^{1,2}$ and Norio NirKaWA ${ }^{1}$ \\ Departments of ${ }^{1}$ Human Genetics and ${ }^{2}$ Pediatrics, Nagasaki University School of Medicine, \\ Sakamoto-Machi, Nagasaki 852, Japan \\ ${ }^{3}$ Cytogenetics Research Laboratory, Kyushu Medical Science, \\ Matsushima, Fukuoka 813, Japan
}

\begin{abstract}
Summary A 5-year-old boy with multiple congenital anomalies showed a satellited long-arm chromosome 9, a previously undescribed abnormality. Various banding analyses of his chromosomes and those of his parents indicated that a reciprocal translocation, $\mathrm{t}(9 ; 22)(\mathrm{q} 34.3 ; \mathrm{q} 11.21)$, occurred in the father's gonad, and one of the translocation chromosomes was then transmitted to the patient. Thus, the patient's karyotype was interpreted as $46, \mathrm{XY},-9,+$ psudic $(9), \mathrm{t}(9 ; 22)(\mathrm{q} 34.3 ; \mathrm{q} 11.21)$. He showed several features similar to those of the Williams syndrome. The gene(s) responsible for the syndrome thus could be at either 9q34.3-qter or 22pter-q11.2. Southern blot analysis of the patient's DNA indicated the presence of two copies of the argininosuccinate synthetase gene which had been assigned to $9 \mathrm{q} 34.1$-qter. In view of the fact that the $9 \mathrm{q} 34.3$-qter segment is monosomic in the patient, the gene locus was deduced to be at 9q34.1-q34.2 segment. Key Words satellited chromosome 9, unbalanced translocation, Williams syndrome, argininosuccinate synthetase gene
\end{abstract}

\section{INTRODUCTION}

Satellited chromosomes other than the acrocentric chromosomes, i.e., those that bear the satellites and satellite-stalks at the end of either arm, are rare. Those reported include 17 individuals with satellited Yq (Schmid et al., 1984), a woman with a 45,X/46,X,Xps karyotype (Stetten et al., 1986), and a woman with a balanced

Received August 29, 1989; revised version received November 6, 1989; Accepted November 21, 1989.

This study was supported in part by a Grant-in-Aid for Scientific Research from the Ministry of Education, Science and Culture of Japan (No. 63480472) and by a Grant entrusted from Kyushu Medical Science.

Offprint requests to Naoki Harada, Department of Human Genetics, Nagasaki University School of Medicine, Sakamoto-Machi, 12-4, Nagasaki 852, Japan. 
translocation $\mathrm{t}(9 ; 13)(\mathrm{p} 11 ; \mathrm{p} 12)$ and her son with an unbalanced karyotype -13 , $+\operatorname{der}(13), \mathrm{t}(9 ; 13)(\mathrm{p} 11 ; \mathrm{p} 12) \mathrm{mat}$ (Varley et al., 1981).

We encountered satellited chromosome 9 in a patient with multiple anomalies. This report deals with the origin of the satellited chromosome 9.

\section{MATERIALS AND METHODS}

Clinical data. The patient was born with a weight of $3,550 \mathrm{~g}$ to healthy and unrelated parents. A cyanotic spell was noted two hours after birth. He suffered from marked failure to thrive during infancy and from growth and developmental retardation.

When seen by us at age 5 years, he measured $90.2 \mathrm{~cm}(-4.1$ S.D.) and weighed $13.6 \mathrm{~kg}(-2.0 \mathrm{~S} . \mathrm{D}$.). His facies resembled that in the Williams syndrome (Preus, 1984) with frontal bossing, a hirsute forehead, hemangioma at the midline of the forehead, arched eyebrows, synophrys, long eyelashes, hypertelorism, downward slanting palpebral fissures, eversion of the lower lateral palpebrae, a pinched nose, a depressed nasal bridge, anteverted nostrils, malar hypoplasia, a deformed right ear with a skin tag, a protruding maxilla, full lips, a fish-like protruding mouth, prognathism (Fig. 1) and widely spaced teeth. His fingers were tapered and his feet were fibularly deviated. His skin was dry and ichthyotic. He had bilateral conductive hearing loss ( $50 \mathrm{~dB}$ on the right and $70 \mathrm{~dB}$ on the left). Frequently noted were paroxysmal dyspnea and cyanosis, arrhythmia during sleep, and myoclonus of the upper extremities. Laboratory examination revealed idiopathic hypercalcemia $(17.0 \mathrm{mg} / \mathrm{dl})$. The results of analysis for organic acidemia were negative. Cardiac examination revealed bradycardia and hypertrophic myopathy but no evidence of a supra-aortic valvular stenosis. Repeated computerized tomo-

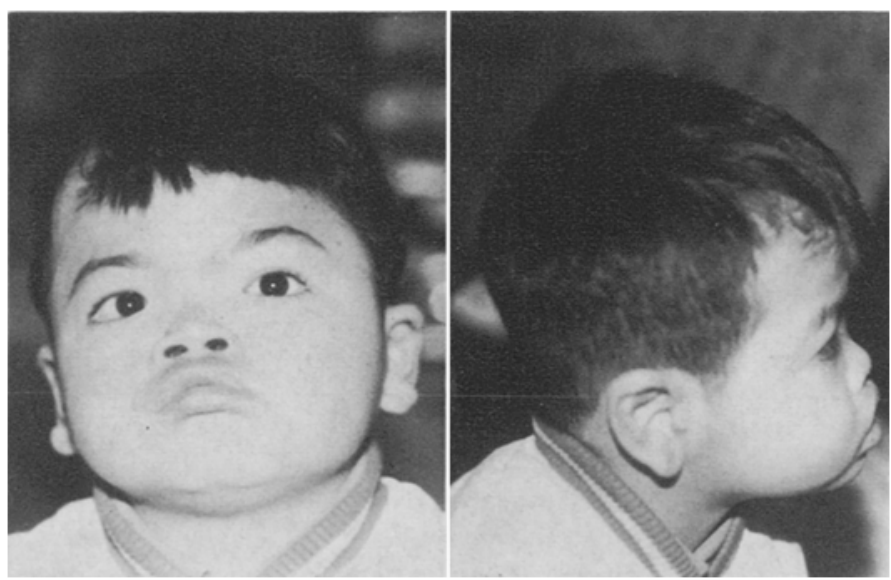

Fig. 1. The patient. 
graphy revealed progressive brain atrophy. Intravenous pyelography showed dilatation of the ureters. The motor nerve conduction velocity was decreased at $34.94 \mathrm{~m} / \mathrm{sec}$ for Nervus medianus, $39.28 \mathrm{~m} / \mathrm{sec}$ for Nervus ulnaris, and at $42.41 \mathrm{~m} / \mathrm{sec}$ for Nervus fibularis.

Cytogenetic study. His peripheral blood lymphocyte chromosomes were analyzed with conventional Giesma-staining, GTG-, QFQ-, RFA-, Ag-NOR-, Cd-, Distamycin A/DAP I-, and AluI-banding (Babu et al., 1988) and with high-resolution GTG-banding. Also analyzed were cells from cultures with folic acid-free medium (MEM-FA, Nissui, Tokyo) supplemented with either $5 \%$ fetal calf serum or with a medium supplemented with $25 \mathrm{ng} / \mathrm{ml}$ fluorodeoxyuridine $24 \mathrm{hr}$ prior to harvest. Chromosomes of the parents were analyzed with GTG-, Distamycin A/DAPI-, QFQ-/RFA-, and AluI-banding.

Molecular analysis. Genomic DNA extracted from the patient's peripheral blood leukocytes was digested by a restriction endonuclease, HindIII. The digests were loaded on $0.8 \%$ agarose gel, electrophoresed, denatured and transferred onto nylon membrane with the Southern blotting technique. Prehybridization, hybridization, washing and autoradiography were performed according to the conditions described previously (Matsumoto et al., 1988). The probe used was AS5'e, a subclone of a repeat and exon-free genomic fragment of the argininosuccinate synthetase (ASS) gene (Jinno et al., 1985), which had been assigned to 9q34-qter (Human Gene Mapping 9, 1987). HindIII fragments of the cDNA (pPA1) of the prealbumin gene located at 18q11.2-q12.1 (Jinno et al., 1986) were used as an internal control for densitometric analysis.

\section{RESULTS}

Conventional Giemsa-stained and GTG-banded metaphases of the patient showed a modal chromosome number of 46 with a chromosome 9 bearing satellites at the distal end of its long-arm (Fig. 2a). The assumption that the satellites were derived from an acrocentric chromosome was supported by the presence of satellites in all cells analyzed regardless of the culture medium used. The presence of both silver dots with Ag-NOR banding (Fig. 2c) and centromere dots with Cd-banding (Fig. 2d), as well as their frequent association with other acrocentrics also support the assumption. The abnormal chromosome was absent in the karyotypes of the patient's parents. The centromeric dots observed at $9 q$ were situated apart (Fig. $2 \mathrm{~d}$ ), and thus the centromere of the translocated segment was assumed inactivated. High-resolution banding analysis of the satellited chromosome revealed that the breakpoint in the chromosome 9 was $9 \mathrm{q} 34.3$ and that in the acrocentric was ?q11.2 (or ?q11) (Fig. 2b). This would indicate that the 9q34.3-qter segment was missing.

Analysis of banding heteromorphisms was performed on each of the patient's acrocentric chromosomes and those of his parents, using sequential QFQ- and RFA-banding (Kamei et al., 1986). QFQ-heteromorphisms at 9q34.3 in the patient 


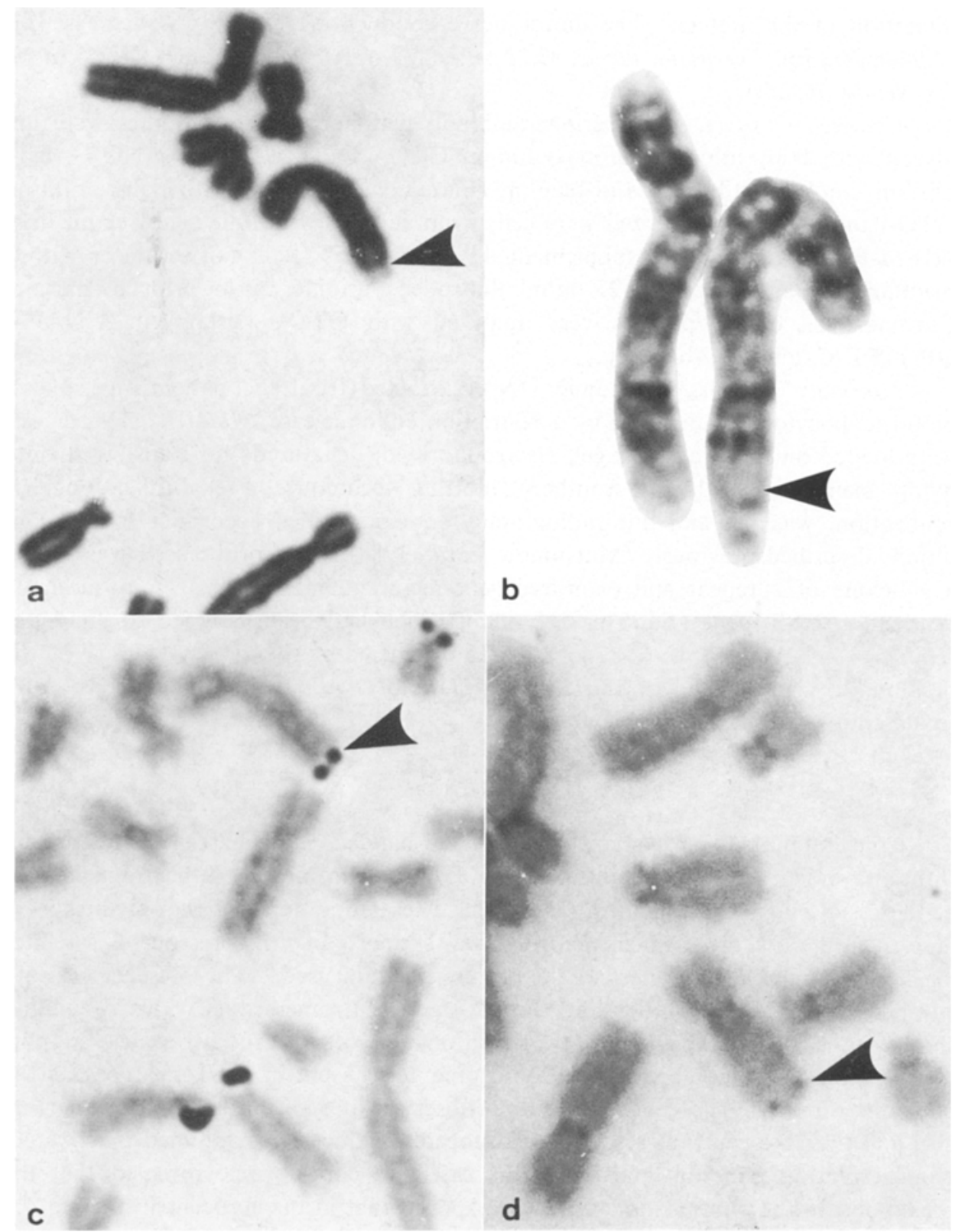

Fig. 2. Satellited chromosome 9 of the patient. Fragile site-like fragments observed with conventional Giemsa-staining (a) and high-resolution GTG-banding (b), silver dots (nucleolar organizer region, NOR) with Ag-NOR banding (c), and centromere dots (Cd) with $\mathrm{Cd}$ banding (d). Note the separated centromere dots. 


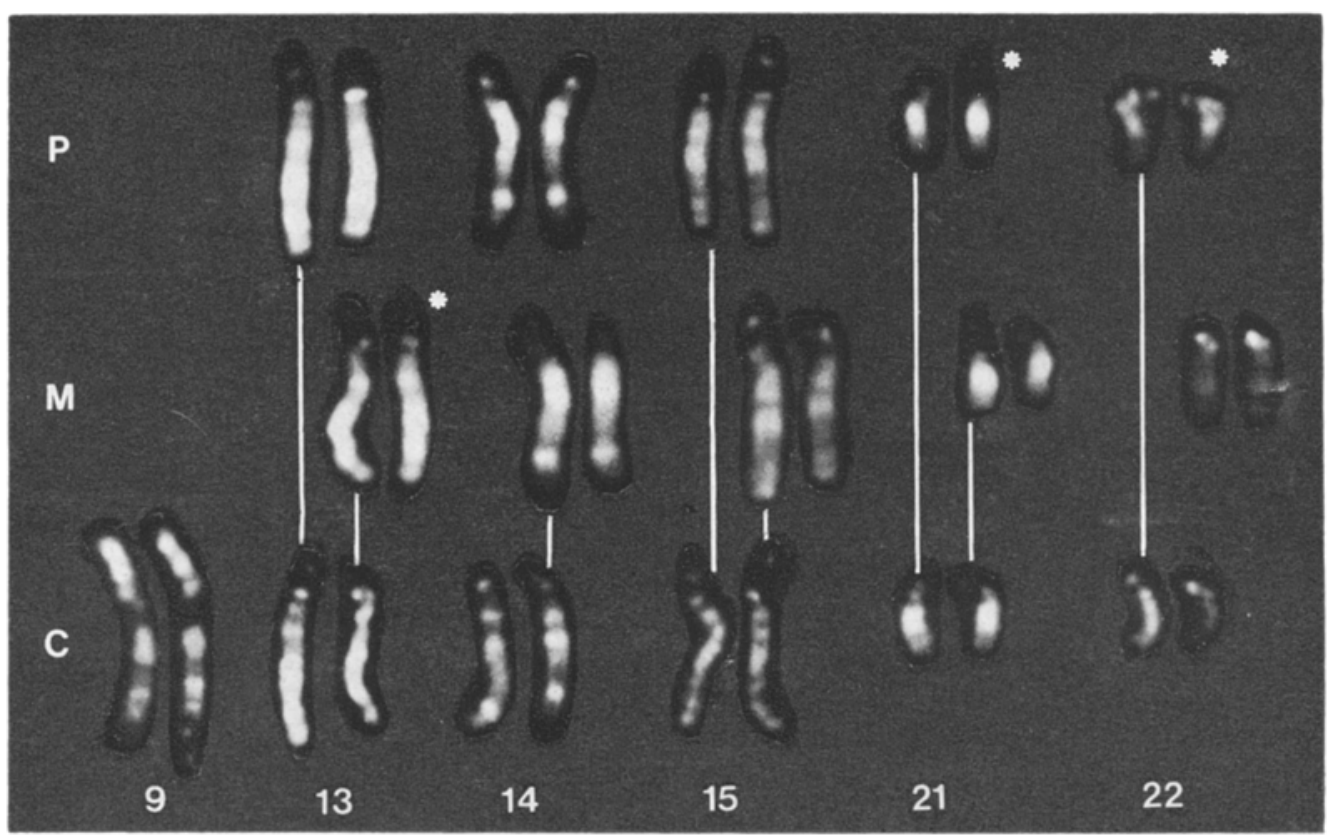

Fig. 3. Transmission of QFQ-heteromorphisms from the father (P) and mother (M) to the patient (C). Transmission of parental chromosomes to the patient is indicated by white lines and the chromosomes possibly translocated onto the patient's chromosome 9 are marked with asterisks.

represented relatively long satellite stalks and moderate fluorescence intensity on the satellites (Fig. 3). Based both on these characteristics and on a priori exclusion, three acrocentric chromosomes thus became candidates involved in the translocation. The three possible chromosomes are: a maternal chromosome 13, a paternal chromosome 21, and a paternal chromosome 22 (Fig. 3). Among these candidates, the paternal chromosome 21 was ruled out by its RFA-heteromorphic pattern (Fig. 4). C-band heteromorphisms by Distamycin A/DAP I-banding and by Alul-banding showed that the satellited chromosome 9 to be paternal in origin (Fig. 5, a and b). One of the paternal chromosomes 9 , as well as satellited chromosome 9 in the patient both had a large C-band block, while the blocks of both maternal chromosomes 9 were small. Assuming that the translocation between the chromosome 9 and an acrocentric chromosome occurred in the paternal gonad, the acrocentric was deduced as a paternal chromosome 22 . Thus, the karyotype of the patient was interpreted as $46, \mathrm{XY},-9,+$ psu $\operatorname{dic}(9), t(9 ; 22)(9$ pter $\rightarrow 9 \mathrm{q} 34.3:: 22 \mathrm{q} 11.21 \rightarrow 22$ pter $)$.

Southern blot analysis of the patient's DNA showed a two copy density of the $7 \mathrm{~kb}$ HindIII fragment of the ASS gene (Fig. 6). 


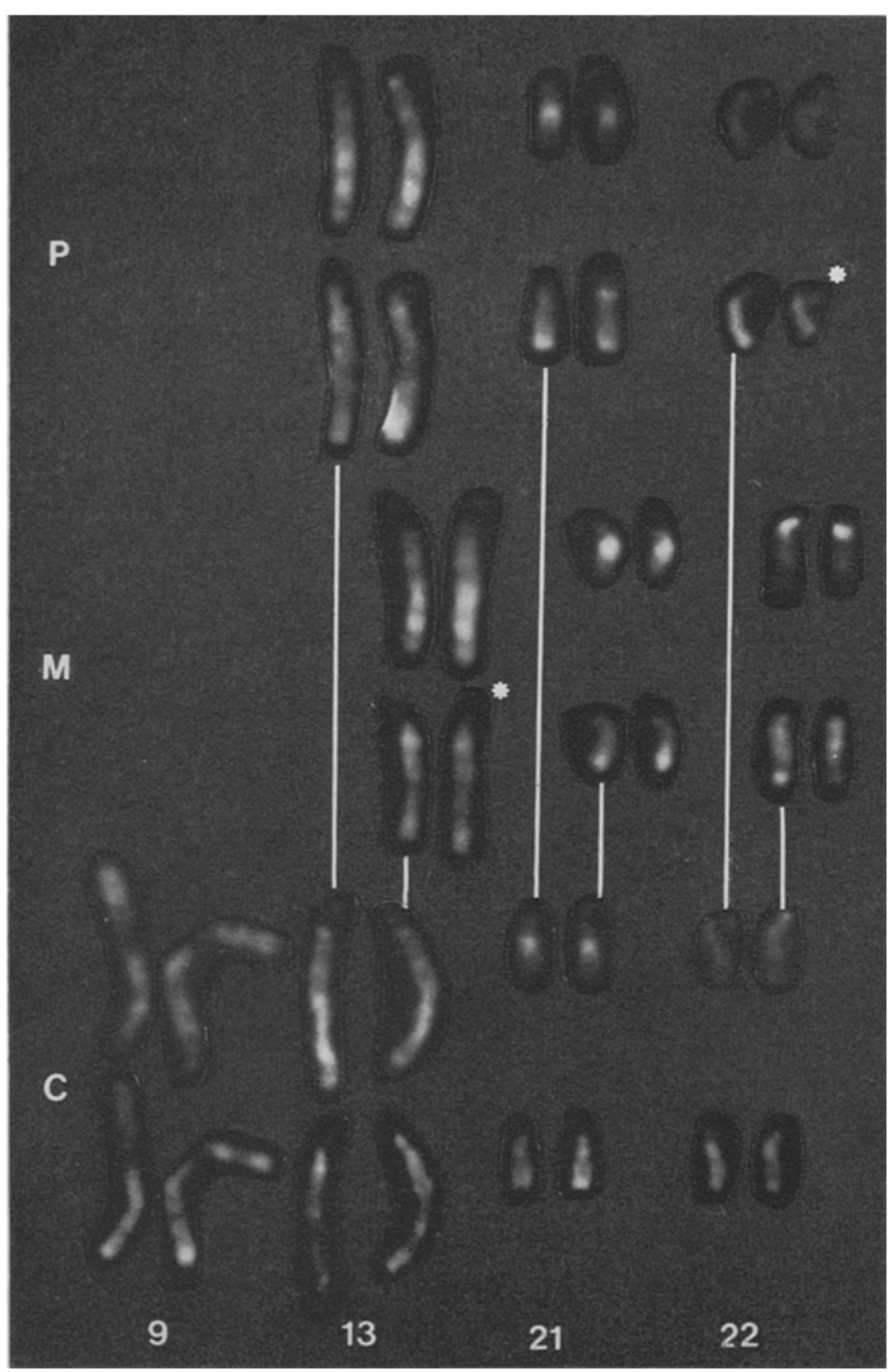

Fig. 4. Transmission of QFQ/RFA-heteromorphisms from parent to child. Parental chromosomes possibly involved in translocation are indicated by asterisks. Upper and lower rows each shows QFQ- and RFA-banded chromosomes.

\section{DISCUSSION}

The result of various banding analyses indicated the occurrence of a translocation involving chromosomes 9 and 22 in a paternal germinal cell, followed by segregation of translocated chromosomes into different daughter cells. This conclusion is supported by previous studies indicating that de novo unbalanced structural ab- 


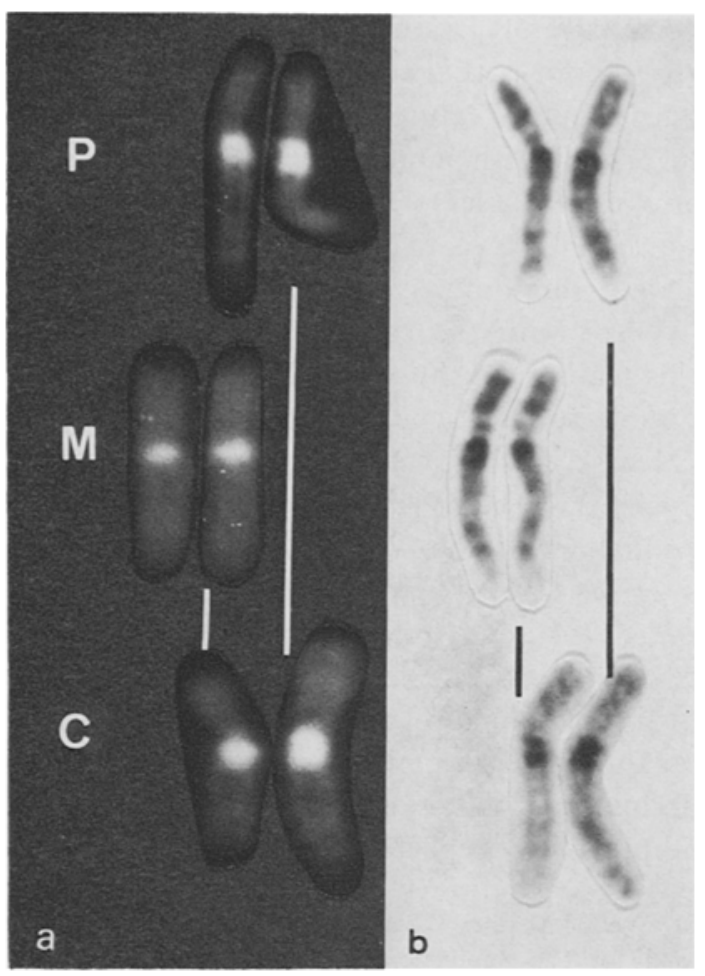

Fig. 5. Transmission of C-band heteromorphisms. Distamycin A/DAPI-banding (a) and with $A l_{t} \mathrm{I}$-banding (b).

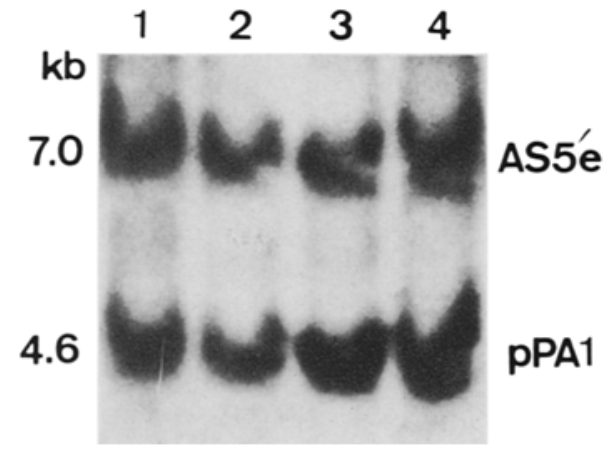

Fig. 6. Scuthern blot bybridization using the genomic fragment (AS5'e) within the argininsuccinate synthetase gene as a probe. Lanes 2 and 3 are for HindIII-digested genomic DNA from the patient, and lanes 1 and 4 are for those from phenotypically normal male individuals. The fragments for pPA1 is an internal control. 
normalities are preferentially of paternal origin (Niikawa and Ishikiriyama, 1985).

The patient showed both partial trisomy 22pter-q11.21 and partial monosomy 9q34.3-qter. Thus, his clinical features may be attributable to either or both of these segments. No patient with monosomy q34.3-qter has been reported in the literature, except for a dozen cases of $\mathrm{r}(9)$ (Borgaonkar et al., 1987). It is likely that the clinical features in our patient resulted from partial $9 \mathrm{q} 34.3$ monosomy, since our patient did not share any symptoms with previous patients with partial trisomy for 22pter-q11 or with the cat-eye syndrome (Schinzel, 1984). In view of the similarity of his features to those of the Williams syndrome, the localization of the gene(s) responsible for the syndrome merits comment. Assuming that our patient is an atypical case of the syndrome, the chromosome segments involved could contain such gene(s). There have been several reports of chromosome abnormalities in individuals with the Williams syndrome. They include $\mathbf{t}(12 ; 15)$ (p11;p11) by Fryns et al. (1982); dup(15)(q12) by Miles and Michalski (1983); $\mathrm{t}(9 ; 17)$ by Martin et al. (1984); del(4)(q33) by Jefferson et al. (1986); del(15)(q11q13) by Kaplan et al. (1987); and del(6)(q22.2q23) by Bzduch and Lukacova (1989). Apparently there is no segment common to all these abnormalities.

Southern blot analysis in our patient indicates that the terminal $9 \mathrm{q}$ segment does not carry the argininosuccinate synthetase gene. This would restrict the locus of the gene from the previously reported $9 \mathrm{q} 34.1-\mathrm{qter}$ to $9 \mathrm{q} 34.1-\mathrm{q} 34.2$.

Acknowledgments We thank Dr. T. Yokoo, Dr. H. Yoshikuni and the nursing staff of Misakae-No-Sono Hospital for The Handicapped Children in Nagasaki for providing clinical data and blood material of the patient.

\section{REFERENCES}

Babu, A., Agarwal, A.K. and Verma, R.S. 1988. A new approach in recognition of heterochromatic regions of human chromosomes by means of restriction endonucleases. Am. J. Hum. Genet. 42: 60-65.

Borgaonkar, D.S., Shaffer, R. and Reisor, N. 1987. Structure variations and anomalies. In Repository of Human Chromosomal Variants and Anomalies. An International Registry of Abnormal Karyotypes, 12th Ed. Med. Cent. Delaware and Univ. Delaware, Newark, pp. 1-762.

Bzduch, V. and Lukacova, M. 1989. Interstitial deletion of the long arm of chromosome 6(q22.2 q23) in a boy with phenotypic features of Williams syndrome. Clin. Genet. 35: 230-231.

Fryns, J.P., Van der Hawwaert, L.G., Dumoulin, M. and Van der Berghe, H. 1982. The elfin face syndrome and the short-arm of chromosome 15. Ann. Génét. 25: 181-182.

Human Gene Mapping 9. 1987. Paris Conference, Ninth International Workshop on Human Gene Mapping. Cytogenet. Cell Genet. 46: 170-187.

Jefferson, R.D., Burn, J., Gaunt, K.L., Hunter, S. and Davison, E.V. 1986. A terminal deletion of the long-arm of chromosome $4[46, \mathrm{XX}$, del(4)(q33)] in a female infant with phenotypic features of Williams syndrome. J. Med. Genet. 23: 474-477.

Jinno, Y., Matsuo, S., Nomiyama, H., Shimada, K. and Matsuda, I. 1985. Novel structure of the 5'end region of the human argininosuccinate synthetase gene. J. Biochem. 98: 1395-1403.

Jinno, Y., Matsumoto, T., Kamei, T., Kondoh, T., Maeda, S., Araki, S., Shimada, K. and Niikawa, N. 1986. Localization of the human prealbumin gene to $18 \mathrm{p} 11.1-\mathrm{q} 12.3$ by gene dose 
effect study of Southern blot hybridization. Jpn. J. Human Genet. 31 : 243-248.

Kamei, T., Okimoto-Lee, S., Sohda, M. and Niikawa, N. 1986. A further improved method for identifying heteromorphism of acrocentric chromosomes. Hum. Genet. 73: 369-371.

Kaplan, N.D.T., Wharton, R., Elias, E., Mandell, F., Donlon, T. and Latt, S.A. 1987. Clinical heterogeneity associated with deletions of the long-arm of chromosome 15: Report of three new cases and their possible genetic significance. Am. J. Med. Genet. 28: 45-53.

Martin, N.D.T., Snodgrass, G.J.A.I., Cohen, R.D., Porteous, C.E., Coldwell, R.D., Trafford, D.J.H. and Makin, H.L.J. 1984. Idiopathic infantile hypercalcemia-A continuing enigma. Arch. Dis. Child. 59: 605-613.

Matsumoto, T., Kondoh, T., Yoshimoto, M., Fujieda, K., Matsuura, N., Matsuda, I., Miike, T., Yano, K., Okuno, A., Aoki, Y., Murano, I., Toyota, S., Ohnishi, S. and Niikawa, N. 1988. Complex glycerol kinase deficiency: Molecular-genetic, cytogenetic, and clinical studies of five Japanese patients. Am. J. Med. Genet. 31: 603-616.

Miles, J.H. and Michalski, K.A. 1983. Familial 15q12 duplication associated with Williams phenotype. Am. J. Hum. Genet. 35: 144A.

Niikawa, N. and Ishikiriyama, S. 1985. Clinical and cytogenetic studies of the Prader-Willi syndrome: Evidence of phenotype-karyotype correlation. Hum. Genet. 69: 22-27.

Preus, M. 1984. The Williams syndrome: objective definition and diagnosis. Clin. Genet. 25: $422-428$.

Schinzel, A. 1984. Catalogue of Unbalanced Chromosome Aberrations in Man, Walter de Gruyter, Berlin.

Schmid, M., Haaf, T., Solleder, E., Schempp, W., Leipoldt, M. and Heilbronner, H. 1984. Satellited Y chromosomes: Structure, origin, and clinical significance. Hum. Genet. 67: 72-85.

Stetten, G., Sroka, B., Schmidt, M., Axelman, J. and Migeon, B.R. 1986. Translocation of the nucleolar organizer region to the human X chromosome. Am. J. Hum. Genet. 39: 245-252.

Varley, J.M., Gosden, J. and Hulten, M. 1981. Familial reciprocal translocation $\mathrm{t}(9 ; 13)(\mathrm{p} 11 ; \mathrm{p} 12)$ investigated by silver staining and in situ hybridization. Hum. Genet. 59: 422-428. 